\title{
LA ESTRATEGIA BRITÁNICA DE APOYO A LAS FAMILIAS MONOPARENTALES A TRAVÉS DEL EMPLEO*
}

\author{
CARMEN RODRÍGUEZ SUMAZA \\ Universidad de Valladolid
}

PALABRAS CLAVE ADICIONALES

Reino Unido, Reforma del Estado de Bienestar,

Política Social, Familias Monoparentales.

\section{ADDITIONAL KEYWORDS}

United Kingdom, Welfare Reform, Social Policy,

Lone Parent Families.

RESUMEN. Uno de los cambios más significativos en la estructura familiar británica en las últimas décadas es el aumento del número de familias encabezadas por un solo adulto. Este crecimiento, singular en el contexto europeo, ha generado en el Reino Unido un intenso debate politico y social. En el artículo se parte del análisis de la evolución del número de familias monoparentales, planteándose a continuación las principales líneas de discusión existentes en torno al tema de la monoparentalidad. Seguidamente se estudia la actual respuesta pública a las necesidades de los progenitores solos y la evidencia en la que se apoya. Las nuevas estrategias de promoción del empleo entre los progenitores solos asumen que el trabajo (remunerado) es la mejor solución a sus problemas. Esta politica no es neutral, pues fuerza a los progenitores solos a dar prioridad a sus responsabilidades como proveedores de recursos económicos frente a las responsabilidades familiares. Los dilemas y cuestiones que este planteamiento suscita son revisados en la parte final del artículo.

E-mail: Sumaza@eco.uva.es

'Esta investigación ha sido realizada durante mi estancia a lo largo del curso 1999-2000 en la Universidad de Oxford (Reino Unido). Quiero expresar mi gratitud a los miembros del Dpto. de Politica Social y Trabajo Social por su hospitalidad, así como agradecer la ayuda y comentarios de Teresa Smith, Michael Noble y Jane Lewis. Así mismo, agradezco la ayuda financiera de la Universidad de Valladolid y el Ministerio de Educación y Cultura, a través del programa de movilidad de investigadores españoles en centros extranjeros. Cualquier error es de mi exclusiva responsabilidad.

* Una versión de este artículo ha sido publicada en Policy Studies, vol. 22, n 2, 2001: 99-118. (http://www.tandf.co.uk).

\section{Revista Internacional de Sociología (RIS)}

Tercera Época, $n^{\circ} 30$, Septiembre-Diciembre, 2001, pp. 209-239. 
RIS

RETISTA INTERNACIONAL DE SOCIOLOCL

$N^{\circ}$ 30. Septiembre-Diciembre. 2001

CARMEN RODRIGULZ SUMAZA

ABSTRACT. One of the most significant changes in the British family structure in the last few decades is the growth in the number of families headed by a lone parent. This paper begins exploring the singular growth and characteristics of lone parent families in Britain within the European context. Secondly, it highlights the political and social debates resulting from the different interpretations of the figures. Finally, it reviews the current public response to lone parents' needs and the evidence that supports it. New policy directions are promoting work among lone parents, assuming that work is the best solution for their problems. This policy is not neutral, as it encourages lone parents to give priority to their responsibilities as income providers through paid work. The dilemmas and questions that this policy rises are also discussed.

\section{INTRODUCCIÓN}

La estructura familiar es una de las variables clave a la hora de "entender el desarrollo de la vida en familia. No es el único factor, ni tampoco el más importante pero, como Acock y Demo (1994) señalan, afecta ciertamente a las relaciones familiares $\mathrm{y}$, consecuentemente, al bienestar personal. La estructura familiar británica ha cambiado extraordinariamente en las últimas décadas, al igual que ha ocurrido en el resto de los países desarrollados occidentales, pasando a ser mucho más diversa y plural.

Uno de los cambios más significativos ocurridos en la estructura familiar británica es el crecimiento en el número de familias monoparentales. El estudio de la monoparentalidad británica es especialmente interesante por varias razones. En primer lugar, el Reino Unido presenta la proporción más alta de familias monoparentales dentro de la Unión Europea y sus características y circunstancias son únicas: a diferencia de lo que ocurre en otros países europeos, el riesgo de pobreza entre los progenitores solos en el Reino Unido es extraordinariamente alto, la participación en el mercado laboral de las madres solas es excepcionalmente baja, la proporción de madres solas jóvenes es mayor y su dependencia de los recursos públicos es muy elevada. Estas cuestiones son revisadas en el primer apartado del artículo.

En segundo lugar, el crecimiento del número de progenitores solos en el Reino Unido ha estado acompañado de un singular debate acerca de la monoparentalidad y de las relaciones familia-Estado. En relación con esta cuestión, en el artículo se presentan y analizan los principales discursos dominantes, la mayoría de los cuales plantean una visión problemática de la monoparentalidad. Este hecho ha resultado ser uno de los determinantes del tipo de políticas públicas dirigidas a las familias monoparentales.

Finalmente, el artículo revisa la lógica que subyace a las políticas públicas dirigidas a las familias monoparentales en la actualidad. Al ser la denominada 'ética del trabajo' uno de los pilares de la reforma del estado de bienestar puesta en marcha por el gobierno laborista británico desde 1997, se presenta el trabajo (remunerado) como la mejor solución a las necesidades de las familias 
monoparentales. La participación de los progenitores solos en el mercado laboral se planteó inicialmente con carácter voluntario, pero están siendo ahora activamente animados a trabajar. La reflexión sobre los dilemas y cuestiones que esta estrategia política plantea constituyen la última parte del artículo.

\section{CARACTERÍSTICAS DE LAS FAMILIAS MONOPARENTALES EN EL REINO UNIDO}

Tanto el número como las características de las familias monoparentales en el Reino Unido son bien conocidas. Varias encuestas proporcionan información detallada y continua sobre ellas ${ }^{2}$, existiendo adicionalmente toda una serie de estudios que, con metodologías mayoritariamente de corte transversal, añaden información más amplia y específica sobre el tema (Bradshaw y Millar, 1991; Marsh y McKay, 1993; McKay y Marsh, 1994; Ford, Marsh y McKay, 1995; Marsh, Ford y Finlayson, 1997).

Las estimaciones más recientes del número de familias monoparentales ${ }^{3}$ muestran que su crecimiento ha sido constante a lo largo de las tres últimas décadas, si bien el ritmo de aumento se ha moderado ligeramente desde 1994. Los datos para 1996 informan que había en esta fecha 1,6 millones de familias monoparentales en el país, y que 2,8 millones de menores vivían en este tipo de familia (casi 1 de cada 5) (Figura 1). Dentro de la Unión Europea, el Reino Unido tiene la proporción más elevada de familias monoparentales ${ }^{4}$ dentro del conjunto de familias con menores, muy por encima de la media comunitaria (Eurostat, 1998). El crecimiento es también evidente en términos relativos: en 1971 el 8\% de las familias con menores estaban encabezados por un progenitor solo, triplicándose esta proporción para 1998-99 (tabla 1).

El perfil de los progenitores solos también ha cambiado con los años, si bien en la mayoría de los casos sigue siendo una mujer. Ha habido un incremento en la proporción de madres divorciadas y solteras, mientras que las proporciones de separadas y viudas han disminuido. El aumento más reciente en el número de madres solas es consecuencia fundamentalmente de rupturas de parejas de

\footnotetext{
${ }^{2}$ Tales como la Encuesta de Presupuestos Familiares (Family Expenditure Survey), la Encuesta de Población Activa (Labour Force Survey) o la Encuesta General sobre los Hogares (General Household Survey).

${ }^{3}$ Según la definición del antiguo Dpto. de Salud y Seguridad Social (DHSS, 1974), una familia monoparental consiste en una madre o un padre viviendo sin pareja con sus hijos solteros dependientes, o hijos entre 16 y 19 años estudiando a tiempo completo.

${ }^{4}$ En este caso los hijos dependientes se definen como viviendo en el domicilio de sus padres, sin recursos económicos propios y menores de 25 años.
} 
Figura 1.

Estimación del número de familias monoparentales (FM) y de hijos dependientes en ellas, Gran Bretaña 1971-96.

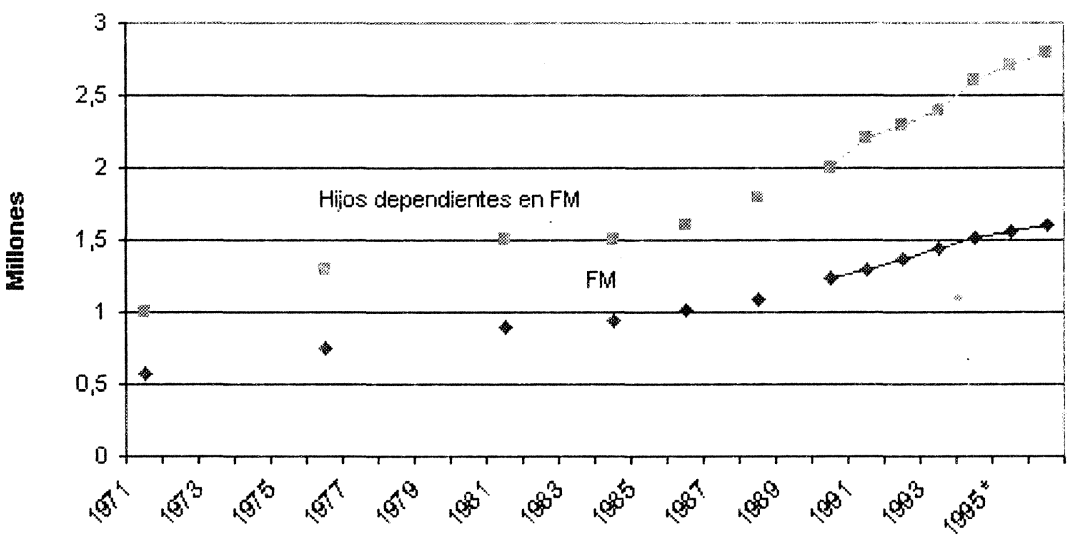

Nota: * A partir de 1995 los datos son provisionales.

Fuente: Haskey, 1998.

hecho, mientras que en los años setenta y ochenta la mayoría de madres solas procedían de rupturas de uniones matrimoniales.

La mayor parte de los intentos de conocer los cambios en las características de los progenitores solos se centran en el análisis de su perfil demográfico, su relación con la actividad económica y su situación económica, aunque también se estudian otras variables como el nivel educativo, las fuentes de ingresos, la propiedad de la vivienda, la composición de la unidad familiar y del hogar monoparental. En la mayoría de las ocasiones esta información se emplea para comparar entre sí los diferentes tipos de familias monoparentales y para establecer las diferencias entre éstas y las familias nucleares conyugales. Algunos resultados destacables son:

- La propensión de las madres británicas con pareja a trabajar fuera del hogar ha aumentado constantemente en los últimos veinte años, mientras que la tasa de empleo de las madres solas ha experimentado la tendencia contraria (Marsh y McKay, 1993; Bradshaw et al., 1996; Haskey, 1998).

- Los ingresos de las madres solas que tienen un empleo son muy bajos (Bryson, 1998; Finlayson y Marsh, 1998).

- Normalmente las fuentes de ingresos de las madres solas son múltiples, siendo las más importantes las transferencias públicas, las pensiones alimenticias y los ingresos procedentes del trabajo (Lewis y Hobson, 1997; Duncan y 
Tabla 1.

Familias con hijos dependientes* ${ }^{*}$ según tipo de familia y estado civil de las madres solas, Gran Bretaña 1971-99 (\%)

\begin{tabular}{lccccccc}
\hline & 1971 & 1976 & 1981 & 1986 & $1991-92$ & $1996-97$ & $1998-99$ \\
\hline $\begin{array}{l}\text { Madre sola } \\
\quad \text { Soltera }\end{array}$ & 1 & 2 & 2 & 3 & 6 & 7 & 9 \\
$\quad$ Viuda & 2 & 2 & 2 & 1 & 1 & 1 & 1 \\
$\quad$ Divorciada & 2 & 3 & 4 & 6 & 6 & 6 & 8 \\
$\quad$ Separada & 2 & 2 & 2 & 3 & 4 & 5 & 5 \\
$\quad$ Todas las madres solas & 7 & 9 & 11 & 13 & 18 & 20 & 22 \\
Padre solo & 1 & 2 & 2 & 1 & 1 & 2 & 2 \\
Pareja casada o cohabitante** & 92 & 89 & 87 & 86 & 81 & 79 & 75 \\
Todas las familias & 100 & 100 & 100 & 100 & 100 & 100 & 100 \\
con hijos dependientes & & & & & & & \\
\hline
\end{tabular}

Notas: "Hijos dependientes son aquellos con menos de 16 años, o que tienen entre 16 y 18 , pero están estudiando a tiempo completo y residen en el hogar familiar. ** Incluye a las mujeres casadas cuyos maridos no figuran como residiendo en el hogar familiar. Fuente: ONS (2000).

Edwards, 1997b; Finlayson y Marsh, 1998; Jarvis y Jenkins, 1998). No obstante, una proporción muy elevada de ellas tiene como únicos o principales ingresos los subsidios públicos (Marsh, Ford y Finlayson, 1997; ONS, 2000).

- El nivel medio de formación de las madres solas es bajo (Bryson, 1998).

- Existe una enorme desigualdad entre el nivel de ingresos de la familias encabezadas por dos progenitores y las encabezadas por un único progenitor (Bradshaw y Millar, 1991; Middelton y Ashworth, 1998; Bradshaw, 1998b).

- Considerando todos los tipos posibles de familias, las monoparentales presentan las mayores proporciones y niveles de pobreza (Millar, 1992; Kiernan et al, 1998; Bradshaw, 1998b; DSS, 2000).

Lógicamente, muchas de las características citadas están relacionadas entre $\mathrm{si}^{5}$, pero lo importante es que ponen de relieve dos cuestiones fundamentales: una situación económica generalmente precaria de las familias monoparentales (especialmente de las encabezadas por una mujer) y unos elevados niveles de dependencia de recursos externos, fundamentalmente provenientes del Estado.

Un reciente estudio sobre los niveles de exclusión social en los Estados miembros de la UE viene a confirmar la primera de estas conclusiones, señalando

\footnotetext{
'Por ejemplo, un bajo nivel de formación puede explicar, ceteris paribus, un bajo estatus ocupacional, una baja remuneración y una elevada tasa de desempleo.
} 
la sobrerrepresentación de los hogares monoparentales en el conjunto de hogares por debajo del umbral de pobreza en toda la Europa comunitaria, pero especialmente en el Reino Unido (Eurostat, 2000). Por su parte, la tabla 2 muestra que, aunque casi un $60 \%$ de las familias en este país recibió algún tipo de subsidio entre 1997-98, los perceptores de prestaciones económicas compensatorias de bajos niveles de ingresos son mayoritariamente hogares monoparentales.

Los datos que habitualmente proporcionan las encuestas y estudios de corte transversal permiten obtener información bastante precisa acerca del número y las características de los progenitores solos en momentos determinados del tiempo, sin embargo no permite capturar otras dimensiones de la monoparentalidad. Es por eso que en los últimos años algunos investigadores han pasado a centrarse en la faceta dinámica de la monoparentalidad, es decir, en el estudio de loš procesos a través de los cuales las personas se convierten en progenitores solos (las vías de acceso a la monoparentalidad) o dejan de serlo. Como estos procesos son variados y complejos, los métodos para medir la contribución de los distintos factores al crecimiento de la monoparentalidad implican el empleo conjunto de metodologías cuantitativas y cualitativas, el recurso al análisis multivariante, a las historias de vida, el empleo de series de tiempo, etc.

Tabla 2.

Beneficiarios de determinadas prestaciones sociales según tipo de familia, Gran Bretaña 1997-98 (\%)

\begin{tabular}{|c|c|c|c|c|c|c|}
\hline $\begin{array}{r}\text { Ayu } \\
\text { viv }\end{array}$ & $\begin{array}{l}\text { udas a la } \\
\text { ivienda }\end{array}$ & $\begin{array}{l}\text { Reducción de } \\
\text { impuestos locales }\end{array}$ & $\begin{array}{l}\text { Transfe- } \\
\text { rencias }\end{array}$ & $\begin{array}{l}\text { Subsidio de } \\
\text { desempleo }\end{array}$ & $\begin{array}{l}\text { Prestación por } \\
\text { hijo a cargo }\end{array}$ & $\begin{array}{l}\text { Alguna } \\
\text { prestación }\end{array}$ \\
\hline \multicolumn{7}{|l|}{ Parejas } \\
\hline Con hijos dependientes & 8 & 11 & 5 & 3 & 98 & 99 \\
\hline Sin hijos dependientes & 5 & 8 & 4 & 2 & - & 27 \\
\hline \multicolumn{7}{|l|}{ Solteros/as } \\
\hline Con hijos dependientes & s 57 & 63 & 57 & 1 & 98 & 99 \\
\hline \multicolumn{7}{|c|}{ Sin hijos dependientes: } \\
\hline Hombre & 10 & 12 & 6 & 10 & - & 25 \\
\hline Mujer & 10 & 12 & 8 & 5 & - & 25 \\
\hline Todas las familias** & 14 & 19 & 11 & 4 & 23 & 59 \\
\hline
\end{tabular}

Notas: "La prestación por hijo a cargo tiene carácter universal. " Las sumas se calculan teniendo en cuenta que una unidad familiar puede recibir más de una prestación.

Fuente: ONS (2000); Datos del Family Resources Survey (DSS). 
Los análisis dinámicos han puesto de relieve dos importantes rasgos. En primer lugar, invitan a considerar la monoparentalidad fundamentalmente como un estadio en el ciclo de vida familiar, más que como un estatus permanente. Como varios trabajos señalan, una proporción significativa de familias monoparentales pasa a constituir otra estructura familiar, ya sea porque el progenitor se empareja de nuevo o ya sea porque los hijos dejan de ser dependientes. La duración media de la estructura monoparental viene a ser de unos cuatro años, si bien hay una amplia dispersión en torno a ese valor medio (Ford, Marsh y McKay, 1995; ESRC, 1994; Noble, Smith y Cheung, 1998). Los flujos de acceso a la situación de monoparentalidad y los de salida de la misma varían según las características personales de los progenitores: estado civil, edad, nivel de estudios, número de hijos, etc. (Ermish, 1991; Ermish, Jenkins y Wright, 1990).

En segundo lugar, la perspectiva dinámica ha aportado evidencia de otra característica estrechamente relacionada con la anterior: el hecho de que el reciente aumento de la monoparentalidad es debido más a un incremento del número de mujeres que pasan a ser madres solas que a un aumento en la duración de la situación de monoparentalidad (McKay y Rowlingson, 1998; Rowlingson y McKay, 1998). Es importante tener este dato en cuenta cuando analicemos algunas ideas generalizadas acerca de la supuesta dependencia de largo plazo de los fondos públicos de las madres solas en la siguiente sección.

Como hemos comprobado, la naturaleza dinámica de la monoparentalidad obliga a tener en consideración los procesos de acceso y salida de dicha situación y las duraciones de este estadio en el ciclo de vida familiar. Parece estar claro que cualquier intento de comprender en su compleja dimensión el fenómeno de la monoparentalidad ha de incluir un estudio del número y características de familias monoparentales existentes, pero también exige analizar sus procesos de formación, las estrategias a las que recurren mientras permanecen en dicha situación y las circunstancias en que pueden terminar constituyendo una diferente estructura familiar.

\section{REPRESENTACIONES SOCIALES DE LA MONOPARENTALIDAD EN EL REINO UNIDO}

Las familias monoparentales, una forma familiar que siempre ha existido, han constituido un importante foco de interés colectivo en muchos países occidentales a finales del siglo XX. Con toda seguridad el crecimiento del número de familias encabezadas por un solo adulto ha contribuido a hacer más visible el fenómeno en términos cuantitativos, pero otros factores relacionados con sus características y circunstancias explican también su controvertida presencia en los debates públicos, especialmente en los países anglosajones. El caso del Reino Unido 
constituye un ejemplo paradigmático, dados los discursos enfrentados que han venido existiendo en torno a la monoparentalidad, o más concretamente en torno a la monomarentalidad.

En la década de los noventa han proliferado los trabajos que han analizado las representaciones sociales de la monoparentalidad en diferentes contextos, principalmente con el objetivo de poder entender la presión social a la que estaban sometidas las madres solas y para poder interpretar y evaluar las políticas públicas dirigidas a este colectivo. Así, algunos estudios han investigado las diferentes actitudes hacia las madres solas en diferentes países (Millar, 1989; Duncan y Edwards (eds.), 1997) o en grupos con distinta ideología política, creencia religiosa o criterios ético-morales (Silva, 1996). Otros se han centrado en analizar las variaciones a lo largo del tiempo de la construcción social de la monoparentalidad en un único país y han tratado de explorar sus causas y sus consecuencias. Este es el caso de las investigaciones para Gran Bretaña a lo largo del siglo veinte de Fox Harding (1993a y b), Edwards y Duncan (1995), Song (1996), Duncan y Edwards (1997b, 1999), Land y Lewis (1998), Lewis (1989, 1997, 1998, 1999), Lewis y Hobson (1997), Kiernan et al., (1998), Ford y Millar (1998) y Bradshaw (1998a). Todas ellas han mostrado que ha habido un elevado nivel de preocupación política, incluso un 'pánico moral' con relación a la monomarentalidad que ha sido determinante a la hora de diseñar las políticas públicas dirigidas a los progenitores solos.

En el caso concreto del Reino Unido se pueden identificar varios discursos como representativos de las diferentes construcciones sociales de la monomarentalidad. Sin embargo, el hecho más significativo es que los discursos política y popularmente dominantes han defendido mayoritariamente una visión cambiante pero siempre problematizada de las familias monoparentales, especialmente de las encabezadas por una madre sola. Aunque el 'problema' ha sido definido de muy diferentes formas (Ford y Millar, 1998; Land y Lewis, 1998; Lewis, 1999) y las perspectivas son muy variadas (McIntosh, 1996; Phoenix, 1996; Roseneil y Mann, 1996; Bradshaw, 1998a), se pueden distinguir al menos cuatro fuentes principales de preocupación que a continuación se comentan.

Parte del debate académico y político sobre las madres solas ha empleado argumentos morales y se ha centrado en su supuesta falta de moralidad, responsabilizándolas del deterioro de la vida familiar y social. Contribuciones influyentes, como las de Dennis (1993), Dennis y Erdos (1992) y Morgan $(1995)^{6}$, ayudaron a difundir una imagen estereotipada de las madres solas: personas desempleadas que trataban de vivir a expensas del Estado, un claro ejemplo de la 'infraclase' de Murray $(1990,1994)$. Sus hijos aprenderían su

\footnotetext{
"Promovidos por el Instituto de Asuntos Económicos (Institute of Economics Affairs), de ideología conservadora.
} 
comportamiento antisocial y lo repetirían más tarde. Adicionalmente, la ausencia de un rol masculino en la unidad familiar era vista como desencadenante, entre otros, de delincuencia juvenil. La monomarentalidad minaba la estabilidad social que la familia nuclear conyugal siempre había representado. La solución era, consecuentemente, el retorno a los valores familiares tradicionales (los denominados valores victorianos ${ }^{7}$ ) y a los históricamente hegemónicos roles familiares.

Como Kiernan et al. (1998) han señalado, esta dimensión moral, dominante en los años ochenta y noventa, fue importada de los EEUU. Así, al tiempo que aumentaba la monoparentalidad y el número de nacimientos fuera del matrimonio, las madres solas pasaron a ser vistas como una 'amenaza social'. Hasta entonces las madres solas (la mayoría divorciadas) eran vistas como víctimas pasivas atrapadas en un círculo de pobreza y merecedoras de algún tipo de ayuda. El resultado había sido que las políticas públicas desde finales de los años sesenta y durante la década de los setenta habían afrontado la pobreza de las madres buscando que éstas pudieran vivir autónomamente con sus hijos.

Una segunda fuente de preocupación ha sido el coste económico que las familias monoparentales suponían al erario público, especialmente debatido en los medios de comunicación. Con el crecimiento en el número de familias monoparentales el gasto público en prestaciones sociales también aumentó. La creciente proporción de madres solas preceptoras de prestaciones económicas fue interpretada como la consecuencia de una creciente cultura de la dependencia promovida por el propio sistema de bienestar. En otras palabras, el gasto público destinado a las madres solas era visto no sólo como causante de importantes problemas financieros al Estado, sino como responsable de que un número creciente de mujeres estuvieran 'casadas con el Estado' (Morgan, 1995:72).

Para los defensores de la existencia de graves efectos perversos en el sistema de prestaciones sociales sólo había una prescripción lógica. Ésta se puede encontrar muy claramente formulada en Murray (1994): la reducción o eliminación de los beneficios. La idea de que los progenitores solos estaban convirtiéndose en personas dependientes del estado de bienestar como consecuencia del atractivo que ejercía el sistema de prestaciones sociales está presente en muchas de las declaraciones públicas y líneas de política social de Margaret Thacher. Sin embargo, como Alcock (1996) señala, esta interpretación es el resultado de un modelo extremadamente simple de causalidad social y pone en evidencia una errónea idea acerca de cuáles han de ser los propósitos de

\footnotetext{
'El matrimonio monógamo tradicional con hijos era, en palabras de Murray, 'la forma más satisfactoria de vivir una vida' (Murray, 1994: 15).
} 
la política social. Por un lado, las decisiones de los individuos son complejas, dependiendo simultáneamente de un amplio conjunto de variables sociales, culturales, económicas, etc. Por otro lado, la política social no debería pretender modificar los comportamientos de los sujetos, sino satisfacer sus necesidades.

Es cierto que la proporción de gasto público cuyos beneficiarios eran progenitores solos creció rápidamente en las dos últimas décadas (tabla 3). En 1997-98 las familias monoparentales recibieron casi 10 miles de millones de libras en prestaciones sociales, una cantidad que representaba el $53 \%$ de todo el gasto destinado a familias y un $10,6 \%$ del gasto en protección social del país. Pero estas cifras reflejan no sólo el crecimiento del número de personas viviendo en situación de monoparentalidad, sino también el creciente número de familias monoparentales viviendo en situación de pobreza, coñ sólo un $40 \%$ disponiendo de rentas superiores a la mitad de la renta media nacional en 1996/97 (DSS, 1998).

Tabla 3

Gasto en prestaciones de la seguridad social en términos reales, según grupo de beneficiarios, 1981-1998 (billones de libras a precios de 1997-98)

\begin{tabular}{lrrrr}
\hline & $1981-82$ & $1986-87$ & $1991-92$ & $1997-98$ \\
\hline Personas mayores & 29,7 & 35,1 & 37,2 & 42,8 \\
Enfermos y discapacitados & 7,7 & 11,4 & 15,9 & 24,0 \\
Familias & 10,1 & 12,5 & 13,6 & 18,6 \\
Familias monoparentales & 2,2 & 4,3 & 6,7 & 9,9 \\
Desempleados/as & 7,8 & 11,6 & 8,9 & 6,3 \\
Viudos/as y otros & 2,0 & 2,0 & 2,2 & 2,0 \\
Total & 57,2 & 72,6 & 77,7 & 93,7 \\
\hline
\end{tabular}

Fuente: ONS (2000).

Una tercera fuente de preocupación ha sido el bienestar de los niños que viven en una familia monoparental o experimentan una ruptura familiar, pues existe una idea generalizada de que vivir en este tipo de familias es perjudicial para ellos. Es sin embargo importante ser cuidadosos con esta afirmación, pues resulta muy difícil separar los efectos de un tipo particular de estructura familiar sobre los niños de los efectos de las relaciones familiares o de los recursos a disposición de las familias. 
Son numerosas las investigaciones que defienden la idea de que los menores que viven la ruptura de la relación entre sus padres tienen en mayor proporción algún tipo de problemas: educativos, de conducta, de salud, económicos, etc. (Rodgers y Pryor, 1998). Sin embargo, no hay consenso acerca de con quién habría que comparar a estos niños (Furstenberg y Cherlin, 1991), ni acerca de cuáles son las variables verdaderamente críticas a la hora de explicar sus resultados y su bienestar. Mientras que algunos estudios afirman que las variables más determinantes son las circunstancias y recursos económicos, otros enfatizan la existencia de conflictos en el seno de la familia, el tipo de relación entre padres e hijos, etc. Cuando todos estos factores son simultáneamente tenidos en cuenta, los efectos de criarse en un tipo u otro de familia se reducen significativamente (Acock y Demo, 1994).

Después de revisar estas cuestiones en las investigaciones existentes sobre este tema, Burghes (1994 y 1996) concluye que no hay evidencia robusta para afirmar la existencia de un efecto directo entre la estructura familiar y las vidas de los niños y los progenitores implicados. En cambio, apunta a que factores como el tipo y la calidad de las relaciones familiares o los recursos materiales son variables más significativas que la propia ruptura familiar o la propia estructura familiar. Es más, como confirma Stacey (1994), las situaciones de conflicto que viven muchas familias nucleares pueden perfectamente ser más perjudiciales que una separación bien gestionada. Además, no todas las familias monoparentales son resultado de un proceso de ruptura de pareja.

Finalmente, una cuarta fuente de preocupación han sido los relativamente elevados niveles de pobreza de las familias monoparentales. Tanto si se emplean medidas absolutas como relativas ${ }^{8}$, los resultados muestran de una manera consistente una elevada incidencia de la pobreza en las familias monoparentales (representan una elevada proporción dentro del conjunto de los pobres), un mayor nivel de pobreza que el que presentan otros grupos y una especial concentración de la pobreza en los núcleos encabezados por una mujer (Millar, 1989, 1992, 1996b; Millar y Bradshaw, 1987; Bradshaw y Millar, 1991; Oppenheim, 1998). Las madres solteras son las más pobres del conjunto de madres solas (Kiernan et al., 1998).

Como era de esperar, hay un debate abierto en torno a las posibles interpretaciones de estos datos, sus implicaciones, su interrelación con otras cuestiones de la monoparentalidad y las opciones para aliviar esta situación. Algunos autores consideran que el principal determinante de la precaria situación económica de muchos padres/madres solos no es la monoparentalidad en sí, sino otros

\footnotetext{
${ }^{x}$ Según que la referencia sea un nivel de ingresos determinado o bien el nivel de ingresos medio de la población.
} 
RIS

REVISTA INTERNACIONAL DE SOCIOLOCí

$N^{*}$ 30. Septiembre-Diciembre. 2001

CARMEN RODRIGLLZZ SUMAZ

factores asociados tales como el bajo capital humano que presentan, su escasa participación en el mercado laboral, los trabajos escasamente remunerados que suelen tener, etc. (Bryson et al., 1997; Bryson, 1998). También hay evidencia de que la mayor parte de las madres solteras eran pobres antes de quedar embarazadas, aunque los procesos de ruptura y separación de la pareja son una causa importante de pobreza (Kiernan et al., 1998; Jarvis y Jenkins, 1998). Finalmente, otros autores subrayan el hecho de que los altos niveles de pobreza de las madres solas han de ser entendidos en el contexto de desigualdades por razón de género que existen dentro del matrimonio y en el ámbito del empleo (Millar, 1989; Millar y Glendinning, 1992).

Los estudios comparativos entre países muestran que los niveles de pobreza de las madres solas descienden significativamente si éstas tienen un empleo (Bradshaw, 1998b). El trabajo remunerado es efectivamente una de las vías más importantes para salir de la pobreza, pero también es cierto que en las últimas décadas un número creciente de trabajadores en el Reino Unido se han visto obligados a combinar el empleo con algún tipo de prestación social (ayudas para la vivienda, reducción de impuestos municipales, complementos salariales, etc) como consecuencia de sus bajos salarios. Parece estar claro con ello que el desempleo es una de las principales causas de pobreza, pero que el empleo no es una garantía contra ella. Las ayudas económicas a las personas que trabajan pero no disponen de suficientes ingresos juegan un papel importante a la hora de intentar aliviar la situación de pobreza de muchas madres solas pero, incluso con ellas, muchas no consiguen superar la situación de precariedad económica en que viven (Millar et al., 1997).

La mayoría de los estudios existentes sobre la pobreza de las familias monoparentales miden ésta a través de indicadores de renta e índices de bienestar material. Subyace en ellos la idea de que la principal causa de la pobreza es la falta de dinero. Algunas iniciativas más novedosas enfocan el tema desde una óptica pluridimensional centrándose en el análisis de la calidad de vida de los adultos, ofreciendo esta opción la posibilidad de examinar la importancia relativa de los distintos temas que preocupan a los progenitores solos. Recurriendo a esta perspectiva, McKendrick (1998) concluye que las cuestiones económicas (trabajo, situación financiera, expectativas económicas) constituyen aspectos relativamente menos importantes en sus vidas, mientras que los dominios personales (vida familiar, control sobre su propia vida, etc.) contribuyen en mayor medida a su calidad de vida. Estos resultados apuntan a que, además de las monetarias, otras cuestiones tales como los servicios de atención a los menores, los servicios de salud, el entorno, etc. deberían ser también tenidas en cuenta a la hora de diseñar políticas dirigidas a este colectivo.

Como hemos podido comprobar, el aumento en el número de familias monoparentales en el Reino Unido ha ido acompañado de un vivo debate. Las diferentes interpretaciones acerca de las causas determinantes y de las 
posibles consecuencias reflejan un importante grado de ansiedad social que deriva fundamentalmente del hecho de que las madres solas han sido vistas o bien como un grupo con comportamientos desviados o bien como una minoría en situación de precariedad. Quizás sea la falta de conocimiento o de reconocimiento de la heterogeneidad interna que presenta este colectivo la que ha derivado en una imagen estereotipada de este colectivo que ha subrayado selectivamente algunas de sus características, pero no necesariamente las más relevantes. Efectivamente la maternidad en soltería ha aumentado, pero todavía la mayoría de las familias monoparentales provienen de una separación o un divorcio. Asimismo, tres de cada cuatro niños nacidos fuera del matrimonio son inscritos en el registro por dos progenitores, y la mayoría de ellos residen en el mismo hogar. Las madres solas adolescentes representan tan solo una pequeña parte del total de madres solas (ONS, 2000).

Las diferentes representaciones sociales de la monoparentalidad y sus variaciones a lo largo del tiempo pueden ser vistas como una prueba de que la familia es no sólo una institución social sino también, como bien expresa McIntosh (1996), una 'fantasía colectiva'. En otras palabras, las diferentes imágenes de la monoparentalidad, particularmente aquéllas que resultan de generalizaciones de casos extremos, pueden desembocar en representaciones patológicas, problematizadas o estigmatizadas de los progenitores solos que pueden resultar tan irreales como la imagen idealizada de las familias nucleares con las que frecuentemente se las compara. Como veremos en la siguiente sección, estos discursos sociales vigentes permiten comprender la lógica que subyace a las políticas sociales dirigidas a las familias monoparentales.

\section{RESPUESTA PÚBLICA A LAS NECESIDADES DE LAS FAMILIAS MONOPARENTALES}

Las políticas públicas destinadas a las familias monoparentales han constituido y constituyen en el Reino Unido un tema muy controvertido pues, dependiendo de la interpretación personal y/o colectiva de la monoparentalidad que se hace, son vistas como una inaceptable y perversa forma de pagar con dinero público las consecuencias de decisiones privadas, o como un instrumento necesario para enfrentarse a las dificiles circunstancias que muchas de estas familias viven. Pero incluso cuando se mantiene una opinión favorable a la existencia de ayudas, hay una tremenda variedad de opciones relativas a las características que éstas han de tener.

Existe ya un número significativo de trabajos que analizan el reto que las familias monoparentales han ido suponiendo a los responsables de la política social británica y las políticas públicas que se han ido implementando en respuesta (Popay et al., 1983; Burghes, 1993; Bryson et al., 1997; Millar, 


\section{R I S}

1989; Lewis, 1998; etc.). Tal y como señalan Kiernan et al. (1998), el Gobierno británico mantuvo durante mucho tiempo una singular neutralidad frente al papel de las madres solas como trabajadoras y como cuidadoras. A diferencia de otros países, los progenitores solos británicos han tenido derecho desde 1948 a percibir una prestación económica hasta que su hijo menor tuviera 16 años. Esta medida fue en su día el resultado de la prevalencia de la idea de que los progenitores solos no debían ser empujados a buscar un empleo tras el acontecimiento que provocara la situación de monoparentalidad (pérdida del cónyuge, ruptura matrimonial, nacimiento de un hijo fuera del matrimonio, etc.) en su interés y en el de sus hijos. Pero desde finales de los ochenta, y claramente desde los recientes programas de reforma del estado de bienestar, las medidas de política indican una clara intención de insertar a las madres solas en el mercado de trabajo?.

Esto es lo que está ocurriendo con las nuevas medidas dirigidas a las familias monoparentales solos en los cuatro últimos años. Desde 1997, el Gobierno laborista ha planeado una reforma del estado de bienestar y uno de los principales compromisos es la promoción de la autonomía financiera de los sujetos a través del empleo. Con las políticas del programa welfare-to-work ('del subsidio al empleo'), el Gobierno busca reducir el número de personas que reciben transferencias como consecuencia de que carecen de recursos por la vía de que éstas pasen a disponer de un empleo. Estas medidas supuestamente reportan beneficios a los individuos (no sólo en términos económicos, sino psicológicos, relacionales, etc.), al Estado (más personas trabajando suponen una reducción de los gastos sociales y un aumento de los ingresos por impuestos vinculados a las rentas del trabajo) y para la economía y la sociedad en su conjunto (los niveles de pobreza se reducen y más gente pasa a desempeñar un papel activo en la vida económica y social).

Uno de los grupos objetivo de la política del welfare-to-work lo constituyen los progenitores solos. El gobierno británico ha desarrollado una iniciativa específica dirigida a ellos denominada el New Deal for Lone Parents (NDLP) ('Nuevo Acuerdo para los Padres/Madres Solos'), aunque otras reformas en marcha ${ }^{10}$ también buscan favorecer su tránsito hacia el empleo ${ }^{11}$. La mayoría de los progenitores solos ya eran candidatos a participar en programas previos, pero

\footnotetext{
"En Ford y Millar (1998) se puede encontrar un buen resumen de las principales iniciativas en materia de seguridad social que afectaron a las familias monoparentales entre 1988 y 1998.

11) Como las nuevas medidas tendentes a facilitar la compatibilidad entre las responsabilidades familiares y laborales o las medidas para mejorar las condiciones del empleo y los salarios.

11 Para una análisis actualizado y completo de las políticas británicas del actual Gobierno laborista con efecto sobre las familias monoparentales, ver Rodríguez Sumaza (2001).
} 
como grupo objetivo ahora son activamente alentados formar parte y reciben ayuda personalizada. Aunque el esquema diseñado era inicialmente voluntario para los progenitores solos con hijos mayores de 6 años, desde abril de 2000 los nuevos solicitantes de prestaciones han de asistir a una entrevista de orientación laboral. Los progenitores solos con niños entre 3 y 5 años han sido recientemente invitados a incorporarse al programa y también a ellos se les anima a incorporarse activamente al mercado de trabajo. Esta política refleja claramente la influencia de la política social norteamericana de los últimos años, donde los programas de reducción de la pobreza exigen a los sujetos estar vinculados al mercado laboral.

Concretamente, la promoción de la participación laboral de las madres solas (cuya presencia era escasa en el mercado laboral) ha desencadenado en el Reino Unido un intenso debate en el que se plantean múltiples interrogantes: ¿es el empleo la mejor manera de mejorar el bienestar de las familias monoparentales? ¿qué factores explican verdaderamente el bajo nivel de participación de las madres solas en el mercado de trabajo? ¿hasta qué punto son las prestaciones económicas del Estado las que animan a las madres solas a no buscar un empleo?....

La política diseñada por el nuevo Gobierno laborista para progenitores solos entiende la participación de éstos en el mercado laboral en términos de racionalidad económica como un comportamiento sujeto a una serie de condicionantes. Las bajas tasas de actividad de las madres solas (y consecuentemente su elevada dependencia de las prestaciones sociales) son vistas como el resultado de la concurrencia de varios factores, algunos de los cuáles actúan a favor de la participación (como 'puentes' desde las prestaciones económicas hasta el empleo) y otros en contra (las 'barreras' al empleo). Siendo esto así, las políticas públicas lo único que han de hacer es abordar adecuadamente estos factores para conseguir el efecto agregado deseado.

Esta comprensión particular del tema se sustenta en una línea reciente de investigación. Gardiner (1997), en uno de los trabajos pioneros, identifica diferentes grupos de 'barreras' y 'puentes' potenciales al empleo para los receptores de prestaciones económicas. Aunque su análisis no busca explicar específicamente el caso de las familias monoparentales, las barreras más relevantes encontradas son las características personales, la responsabilidad del cuidado de dependientes, la incertidumbre acerca del futuro, la falta de información y, por supuesto, la falta de empleos disponibles.

¿Qué se sabe exactamente acerca de las barreras y los puentes para los progenitores solos? Algunos estudios que se han centrado en el análisis de la diferente propensión de las madres solas a participar en el mercado laboral en diferentes países han encontrado que, a pesar de que resulta difícil explicar las diferencias porque un mismo nivel de participación puede ser debido a diferentes causas, variaciones en las características individuales de las madres solas son 
significativas a la hora de explicar las variaciones en los niveles de empleo. Concretamente la edad, el nivel de formación, la experiencia laboral previa y el número de hijos (especialmente el número de hijos en edad preescolar) tiene un efecto muy significativo sobre los niveles de empleo (Bradshaw et al., 1996; Bradshaw, 1998b). Las diferencias dentro del grupo de madres solas pueden ser también importantes, de modo que madres solas con elevado nivel de formación, con hijos mayores, propietarias de su hogar y sin problemas de salud pueden tener unas tasas de ocupación incluso superiores a las de las madres con pareja (Finlayson y Marsh, 1998).

Algunas de las características personales, como por ejemplo la experiencia laboral o la cualificación, condicionan a su vez el salario potencial (Polachek, 1995), es decir, la retribución que supuestamente se obtendría en caso de trabajar. Según Jenkins (1992), Ermish y Wright (1991) y Bryson et al. (1997), cuanto más alto es el salario potencial, mayor es la probabilidad de tener un trabajo y ser económicamente independiente, lo que implica que la formación es una vía importante de mejora de las expectativas laborales de las madres solas. Las madres solas en el Reino Unido presentan efectivamente bajos niveles de capital humano con relación a otros (posibles) trabajadores. Pero siguiendo la trayectoria de una muestra transversal representativa a nivel nacional de madres solas entre 1991 y 1995, Bryson (1998) encontró que la experiencia de la monomarentalidad en sí misma (con la exposición a situaciones complejas que puede suponer y a responsabilidades potencialmente en conflicto) puede limitar el capital humano al dificultar la inversión en educación, la dedicación más intensa a las actividades laborales, etc.

Para afrontar esta barrera, la iniciativa del NDLP ofrece asistencia personalizada en la búsqueda de un empleo y programas de formación e inserción laboral. Al mismo tiempo, otro conjunto de medidas como el nuevo salario mínimo interprofesional o los cambios en el sistema de transferencias a individuos están tratando de mejorar los incentivos económicos de tener un empleo.

La explicación de los bajos niveles de actividad de las madres solas británicas en términos del sistema de prestaciones económicas también tiene una cierta plausibilidad. Diferentes estudios han analizado los incentivos y desincentivos que tiene el sistema de prestaciones sociales británico descubriendo que los desincentivos al trabajo más importantes aparecen cuando los ingresos derivados del empleo no exceden significativamente de las transferencias recibidas del estado, creándose así la denominada "trampa de la pobreza" (Bryson y McKay 1994, 1996). Hay también evidencia de que las dificultades que tienen los sujetos para comprender y gestionar las prestaciones económicas les pueden conducir a no intentar mejorar su situación (Gardiner, 1997).

Son varias las investigaciones que han intentado poner a prueba la supuesta racionalidad de la dependencia de las madres solas de las prestaciones sociales defendida por algunos políticos, medios de comunicación y científicos sociales. 
La evidencia muestra de una manera consistente que las madres solas sí tienen en consideración la cuantía de las prestaciones a la hora de decidir si buscar o no un empleo. Sin embargo, las cuestiones económicas no son las únicas que se sopesan, por lo que las tasas de actividad no pueden explicarse exclusivamente en estos términos. Tal y como señala Joshi (1990), en los años ochenta hubo una reducción importante de los pagos por transferencias a las madres solas y simultáneamente aumentaron las tasas de inactividad y de desempleo de éstas. Es más, afirman Bryson et al. (1997) que las prestaciones económicas sólo tienen un efecto considerable sobre los niveles de empleo si las primeras desaparecen, provocando una situación de penuria económica. Pero la penuria por sí misma (y la angustia que conlleva) reduce las posibilidades de empleo.

Los posibles desincentivos económicos que pueda contener el sistema de prestaciones sociales británico han sido abordados a través de una reforma conjunta del sistema de gastos sociales y de impuestos y a través de un conjunto de medidas que buscan que el empleo provea de ingresos dignos. Los cambios pretenden simplificar los sistemas existentes y facilitar el tránsito hacia el empleo a través de servicios de información e incentivos económicos.

Ciertamente, las transferencias compensatorias de bajos ingresos laborales ${ }^{12}$ facilitan la disposición de los padres/madres solos para buscar un empleo y trabajar y actúan como una red de seguridad que les permite mantenerse en el mercado laboral. Pero también pueden tener efectos perversos, pues pueden impedir que la gente trabaje más que el mínimo de horas requerido si las ganancias de renta neta final son pequeñas (Gardiner, 1997) y pueden forzar a las madres solas a aceptar trabajos mal remunerados, ya que limitan el nivel de los salarios a percibir por los trabajadores (Bryson, 1998). Según Finlayson y March (1998), este tipo de prestaciones sólo ejercen un atractivo muy limitado pues, cuando se está en una situación laboral muy precaria, con baja remuneración, sin cualificación y con horarios de trabajo marginales, muchas madres solas prefieren estar en casa cuidando de sus hijos antes que trabajando fuera, independientemente de que sus salarios se vean luego complementados.

La eficacia del conjunto de prestaciones sociales dirigidas a las madres solas se ve así claramente reducida por sus salarios potenciales y el tipo de trabajo al que pueden acceder. Las consideraciones económicas no son necesariamente los aspectos más importantes tenidos en cuenta ${ }^{13}$. Otras prioridades, como estar en

\footnotetext{
12 Tales como el antiguo Family Credit o el actual Working Families Tax Credit. Son fundamentalmente suplementos salariales para familias con niños y bajos ingresos y que trabajan un mínimo de horas a la semana.

1: McLaughlin, Millar y Cooke (1989) realizan un interesante análisis sobre la forma en que los desempleados perciben los incentivos económicos y cómo afectan a su participación en el mercado laboral.
} 
casa cuidando de sus hijos, o evitar poner en peligro el nivel de ingresos de que se dispone en cada momento o evitar la incertidumbre que suponen los cambios pueden ser también decisiones perfectamente racionales.

Un área de investigación importante en relación con estas cuestiones ha sido también el análisis de los flujos de prestaciones, es decir, el estudio de las entradas y salidas a los programas de prestaciones sociales y de las entradas y salidas al mercado de trabajo. Estos análisis, que son relativamente novedosos en el Reino Unido, parten de datos administrativos complementados con información de encuestas, pero emplean fundamentalmente metodologías longitudinales (Ashworth et al., 1997; Shaw et al., 1996; Noble, Smith y Cheung, 1998). Una de las aportaciones más interesantes de estos trabajos es que han permitido superar la visión estática de las estructuras familiares que proporcionaban los estudios basados en metodologías transversales ÿ además han permitido conocer los comportamientos de los preceptores de prestaciones sociales e identificar las características de los grupos que perciben éstas durante largos períodos de tiempo.

Según los análisis practicados por Noble, Smith y Cheung (1998), hay una enorme variedad de perceptores de prestaciones sociales, lo que prueba que la imagen estereotipada de la madre sola que subyace a muchos discursos sobre la monoparentalidad (joven, soltera, perceptora eterna de prestaciones y que evita a toda costa trabajar) no tiene verdadero fundamento. Aunque es cierto que muchas madres solas solicitan prestaciones económicas, la mayoría dispone de ellas temporalmente hasta que encuentran un trabajo o hasta que se recuperan de una situación de crisis, siendo la duración del estatus de monoparentalidad siempre superior. Adicionalmente, el tránsito de una situación de empleo a una situación de dependencia de las prestaciones sociales no es en la mayoría de los casos la consecuencia de una preferencia por vivir de los recursos sociales, sino fundamentalmente el resultado de la ruptura de una relación de pareja o cuestiones relacionadas con los servicios de atención a menores dependientes o con el trabajo que se tenía. Sólo una pequeña proporción de madres solas (de mayor edad, con mayor número de hijos dependientes, con experiencia laboral reciente escasa y que provienen de una ruptura de pareja) permanecen durante más tiempo percibiendo prestaciones económicas. El estereotipo citado de madre sola no se ajusta pues al perfil del perceptor medio.

Otros dos factores significativos a la hora de explicar la participación en el mercado de trabajo de las madres solas británicas son las responsabilidades de atención y cuidado de los hijos y la oferta existente de servicios destinados al cuidado de los menores. Por un lado, el número de hijos dependiente y su edad ha sido considerado tradicionalmente como una de las principales barreras al empleo para todas las mujeres. Por otro lado, el coste y la disponibilidad de servicios para el cuidado de los menores ha sido citado insistentemente en el caso británico como uno de los principales obstáculos al empleo (Bradshaw y 
Millar, 1991; Bryson et al., 1997), o incluso el principal (Bradshaw et al., 1996; Holterman, 1993). Si en los núcleos monoparentales sólo hay un adulto para trabajar fuera y para atender a los miembros dependientes, las decisiones acerca de si buscar o no un empleo tienen necesariamente que considerar las obligaciones familiares y los costes de oportunidad asociados con el empleo, siendo los servicios de atención a los menores el más importante. Tanto las dificultades de accesibilidad como el coste de estos servicios llevan a muchas madres solas a decidir no trabajar por pura racionalidad económica, sobre todo entre aquéllas que tienen unos ingresos potenciales bajos.

El principal coste asociado al empleo, los servicios de cuidado de menores, ha sido abordado por el Gobierno británico desde dos diferentes ángulos. El primero consiste en una iniciativa a nivel nacional que persigue mejorar la provisión, la calidad y la accesibilidad de estos servicios denominada la "Estrategia Nacional para el Cuidado de Niños" (National Childcare Strategy) (DfEE, 1998). En segundo lugar, se ha puesto en marcha una iniciativa para reducir el coste de estos servicios a través de ayudas para sufragar parte de sus costes si los padres trabajan ${ }^{14}$, aunque sólo incluye servicios oficiales de cuidado de niños y no los arreglos informales entre familiares, amigos, vecinos, etc., que son los más frecuentes.

El papel de los servicios de cuidado de los menores ha sido analizado en detalle por Ford $(1996,1998)$. Según sus conclusiones los servicios de atención a los menores no constituyen la principal razón por la que las madres solas británicas participan menos en el mercado laboral, pero sí es claramente uno de los muchos factores que actúan como obstáculo. La mejora de la oferta de estos servicios es, por tanto, una condición necesaria, pero no suficiente, para la promoción del empleo de este colectivo. El autor subraya el hecho de que un número significativo de madres solas considera que sus hijos son aún demasiado jóvenes para separarse de ella o para recurrir a los servicios externos. La mejora de la disponibilidad de estos servicios y su coste tendrían sólo entonces un impacto relativo en la participación, ya que ésta depende también de la percepción personal de las madres solas acerca de cuáles son verdaderamente las ganancias potenciales (económicas y no económicas) del empleo. Todo esto demuestra que existe todo un complejo conjunto de factores en la balanza.

Enlazando con la cuestión anterior, la orientación hacia el trabajo de las madres solas parece ser otra posible barrera a su vinculación al mercado laboral. Son muchos los trabajos que confirman que las madres solas que no trabajan tienen unas actitudes muy positivas y una buena predisposición hacia el empleo (Bradshaw y Millar, 1991; McKay y Marsh, 1994; Bryson et al., 1997;

\footnotetext{
${ }^{14}$ Para más detalles, ver Treasury (1999 y 2000) y Kelly (2000).
} 


\section{RIS}

Noble, Smith y Cheung, 1998). Sin embargo, algunas dan prioridad a sus responsabilidades como madres y las ven incompatibles con cualquier otra actividad (Duncan y Edwards, 1997b). Este último grupo de madres solas no cree en los supuestos efectos beneficiosos de disponer de un empleo y compartir sus responsabilidades como madres con las propias de un trabajo fuera del hogar. Esta particular valoración del trabajo y la maternidad actúa en contra de la eficacia de las medidas para combatir las barreras al empleo de las madres solas.

El mercado de trabajo donde las madres solas supuestamente deben estar ubicadas también ha sido identificado como otro de los obstáculos potenciales al empleo. En la mayoría de los países europeos, pero especialmente en el caso del Reino Unido, existe un mercado segregado que ofrece trabajos mal remunerados e inestables a una parte de la población que es predominantemente femeñina. Este problema afecta a todas las mujeres, pero coloca en una situación especialmente delicada a las madres solas que son presionadas para trabajar. Además, las oportunidades laborales están también geográficamente repartidas de forma desigual. Esto debería obligar a analizar la participación de las madres solas no a nivel agregado, sino teniendo en consideración los distintos mercados laborales de carácter comarcal, regional o municipal, pues es a estos niveles donde verdaderamente se localizan los recursos y las restricciones (Duncan y Edwards, 1997a). Tanto las condiciones laborales como la vivienda o los servicios de cuidado de menores presentan considerables variaciones a nivel comarcal o regional (Moss, 1991), de modo que el análisis convencional de la monoparentalidad y de las políticas dirigidas a este colectivo debe integrar estas dimensiones espaciales.

Junto al refuerzo de la obligación de las personas de contribuir a la sociedad trabajando, el Gobierno británico ha reforzado su compromiso de mantener la estabilidad macroeconómica y de mejorar las oportunidades de los ciudadanos. Varias iniciativas como el Employment Zones ${ }^{15}$ o el programa Sure Start ${ }^{16}$ están tratando de reactivar las condiciones económicas de zonas deprimidas en todo el país y de impulsar la creación de empleos. Para combatir los prejuicios de los empleadores, agentes del NDLP se ponen en contacto directo con ellos y les informan del proyecto y de los incentivos económicos existentes. Todas las iniciativas se desarrollan a nivel local.

Es justamente a este nivel donde también se sabe que operan factores de tipo informal que configuran la identidad de las madres solas y que determinan y refuerzan sus decisiones de participar o no en el mercado de trabajo. Es el caso

\footnotetext{
${ }^{14}$ El proyecto denominado Zonas de Empleo (Employment Zones) desarrolla en áreas deprimidas programas intensivos e innovadores de lucha contra el desempleo de larga duración. Se puede encontrar información detallada en la dirección: http://www.dfee.gov.uk/ez/
} 
de las redes sociales, otra clave muy importante para entender su propensión a trabajar en términos del apoyo que reciben de su entorno (familia, amigos, vecinos, grupos informales, etc.). La investigación en esta dirección parte de la idea de que la identidad de las personas está significativamente influida por las redes sociales a las que pertenece (Bell y Ribbens, 1994). Las redes sociales y los grupos tienen sus propios discursos prevalentes acerca de la monoparentalidad, generando expectativas acerca de cuál es el comportamiento apropiado de los progenitores solos. Adicionalmente, la familia y los amigos pueden (o no) proporcionar a los progenitores solos apoyo material, constituyendo por tanto un recurso en sí mismos o facilitando el acceso a otros recursos. Transgredir las nociones del grupo acerca de lo que es y significa la maternidad y acerca de la compatibilidad entre familia y trabajo puede implicar costes materiales y psicológicos que muchas madres solas no desean afrontar.

Las investigaciones realizadas en el Reino Unido sobre la identidad de las madres solas y el papel que desempeñan los grupos a los que pertenecen en sus decisiones laborales, basadas en metodologías cualitativas, muestran que la prioridad que dan a la familia o al trabajo está fuertemente apoyada por su entorno más próximo. De ahí que las respuestas de los diferentes grupos de madres solas a los mercados y a las políticas públicas sean tan diferentes en unos contextos y otros (Duncan y Edwards, 1997b).

El NDLP ha sido desde el principio consciente de la necesidad de contar con el apoyo de grupos de influencia próximos a las familias monoparentales, tales como las dos principales organizaciones que las representan a nivel nacional (Gingerbread y el National Council for One Parent Families). Sus programas también intentan influir sobre los progenitores solos que no desean trabajar debido a sus responsabilidades familiares poniendo especial énfasis en los supuestos beneficios del empleo para toda la familia.

Como hemos podido comprobar, las decisiones y el comportamiento en materia laboral de los progenitores solos son cuestiones muy complejas y dependen de un variado grupo de factores que intervienen simultáneamente. De acuerdo con toda la evidencia revisada, las estrategias de promoción del empleo entre los progenitores solos han de plantearse en un contexto amplio, implicando no sólo políticas de empleo, sino también programas que mejoren sus expectativas, que hagan el empleo más atractivo y que faciliten su compatibilidad con las responsabilidades familiares.

El tipo de apoyo que el Gobierno laborista ofrece a las familias monoparentales es el resultado de una forma particular de entender sus problemas y sus

\footnotetext{
${ }^{16}$ El programa Sure Start persigue mejorar los servicios destinados a familias con niños en
} áreas de necesidad (DfEE, 1999). 
RIS

RETISTA INTERNACIONAL DE SOCIOLOCIA

N. 30, Septiembre-Diciembre, 2001

CARMEN RODRIGUUEZ SUMAZA

necesidades. La ética del trabajo que inspira la reforma del estado de bienestar entiende que el trabajo remunerado es la solución a los problemas de los individuos. Como consecuencia los apoyos y las ayudas que se ofrecen se canalizan a través del mercado de trabajo. Esta postura significa que el Estado da creciente prioridad a la responsabilidad de las madres solas como trabajadoras antes que como madres, confirmando la tendencia iniciada en los años ochenta. También significa que el trabajo no remunerado de cuidar a los dependientes no es considerado como un comportamiento ciudadano responsable.

\section{CONCLUSIONES}

En este artículo se ha explorado el incremento del número de familias monoparentales que ha tenido lugar en el Reino Unido en los últimos años y el debate político que ha generado. A continuación se ha analizado la estrategia actual de política social dirigida a este colectivo, intentando destacar sus dimensiones más significativas.

La actual política dirigida a las familias monoparentales descansa sobre dos pilares: las representaciones sociales dominantes de ciudadanía y de monoparentalidad. Por un lado, la centralidad que tiene el trabajo remunerado en la reforma del estado de bienestar hace que éste sea visto como el comportamiento ciudadano responsable por excelencia. El hecho de que se tengan menores dependientes y se sea el principal (a veces el único) cuidador no constituye ya suficiente justificación como para estar fuera de la actividad productiva regulada, lo que da por cerrada la larga tradición británica de apoyo a las madres solas con hijos menores para que se ocuparan directamente de ellos.

Por otro lado, el actual apoyo a las familias monoparentales británicas también ha de ser entendido en términos de cómo la monoparentalidad ha sido y está siendo públicamente definida. Como hemos visto, aunque el clima de opinión ha sido cambiante, ha persistido una interpretación problematizada de la monoparentalidad que, siguiendo la experiencia norteamericana, ha ido dando lugar a políticas sociales cada vez más restrictivas. Su último desarrollo son los recientes programas del welfare-to-work.

Las nuevas políticas entienden que el desempleo de los progenitores solos es una cuestión de barreras al empleo, lo que hace que las distintas medidas estén orientadas a desarrollar estrategias que permitan superar las dificultades que impiden a los prògenitores trabajar. Como las barreras son variadas, las políticas que se están implementando no sólo abordan la empleabilidad de los sujetos, sino también las condiciones del mercado laboral, los servicios de cuidado de personas dependientes, las necesidades derivadas de la combinación de responsabilidades familiares y laborales, etc.

La promoción del empleo entre los progenitores solos británicos plantea 
importantes interrogantes que se encuentran actualmente en debate: ¿Por qué la sociedad no es capaz de considerar que las tareas de cuidado de las personas dependientes que se realizan en el ámbito familiar constituyen en sí mismas un trabajo? ¿Por qué se atribuye a los ingresos monetarios el papel de recurso fundamental en el ejercicio de las responsabilidades paterno-filiales? ¿Es realmente el desempleo la causa principal de la pobreza? ¿Garantiza el empleo la estabilidad financiera y la independencia económica para todo el mundo? ¿Son los servicios de cuidado a menores una responsabilidad pública o privada? ¿Por qué los progenitores solos que atienden en exclusiva a sus hijos no constituyen un adecuado modelo social? ¿Cuál es la principal responsabilidad de un progenitor solo? ¿Hasta qué punto puede el Estado intervenir en las vidas de los sujetos? ¿Por qué la decisión de dedicarse al cuidado de los menores sólo constituye una opción para los progenitores con pareja?, etc.

El análisis del fenómeno de la monoparentalidad constituye un ejemplo paradigmático de la importancia que tiene el estudio de la estructura familiar. En primer lugar, constituye una excelente plataforma para el análisis de la política social. Como hemos visto a través del caso británico, las necesidades de los progenitores solos suponen un verdadero reto a los responsables de la política social, que han de diseñar políticas que combinen adecuadamente la dimensión laboral con otros aspectos relativos al bienestar de los adultos y los niños implicados. En esta línea se plantean las nuevas iniciativas puestas en marcha por el Gobierno británico desde 1997.

En segundo lugar, el estudio de la monoparentalidad constituye una excelente plataforma para analizar las relaciones familia-Estado. La decisión de atender (o no) las necesidades de un determinado tipo de estructura familiar implica una intervención pública en un conjunto de vidas privadas, algo que provoca reacciones contrapuestas. Como hemos visto, las definiciones acerca de lo que son las necesidades y/o los problemas de las familias monoparentales no son neutras. Están determinadas por planteamientos ideológicos y dan lugar a representaciones sociales diversas sobre el papel del Estado y las formas de familia ideales.

En tercer lugar, el estudio de la monoparentalidad es también una excelente plataforma para analizar los roles de género y la naturaleza de los estados de bienestar. Los sistemas de bienestar reflejan modelos culturales que subrayan el papel de las mujeres como madres y/o como trabajadoras. Para reforzar lo que se considera como su principal responsabilidad se desarrollan políticas específicas que perpetúan las diferencias de género. Como hemos comprobado, los progenitores solos británicos están siendo crecientemente alentados a dar prioridad a su responsabilidad como proveedores de ingresos.

Finalmente, el estudio de la monoparentalidad es una excelente plataforma para analizar el empleo y la segregación laboral. La segregación por razón de género de los mercados de trabajo afecta a todas las mujeres, pero especialmente 
a las madres solas que tratan de combinar las responsabilidades familiares con las laborales. La mayoría de los factores que hemos identificado como barreras al empleo de las madres solas británicas pueden ser efectivamente abordados a través de políticas de igualdad de oportunidades entre hombres y mujeres en el empleo.

Los dilemas que plantea la creciente promoción del empleo entre los progenitores solos británicos ponen en evidencia la necesidad de políticas públicas que ciertamente aumenten el campo de elección de los individuos (no que lo reduzcan) y la necesidad de reconocimiento público del valor del trabajo no remunerado de cuidar de los demás. Pero un interrogante fundamental planea tras la reforma: ¿,son los requerimientos de empleo la mejor respuesta a las necesidades de los progenitores solos, dada las dificultades que en su caso plantea la combinación de responsabilidades familiares y laborales? Su crítica posición actual en la sociedad británica podría perfectamente justificar la pervivencia (o incluso ampliación) de los tradicionales apoyos con los que contaban. Pero también es perfectamente posible que la simple mejora de las ayudas a las familias con un único proveedor de ingresos, o con hijos dependientes, o las políticas de lucha contra la pobreza, o contra las desigualdades por razón de género pudieran tener sus efectos beneficiosos sobre las personas que viven en este tipo de estructura familiar.

\section{BIBLIOGRAFÍA}

ACOCK, A.C. y D.H. DEMO (1994), Family Diversity and Well-being, London, Sage Library of Social Research.

ALCOCK, P. (1996), "Back to the future: Victorian values for the $21^{\text {sl }}$ century", en R. Lister (ed.), Charles Murray and the Underclass. The Developing Debate, London, Institute of Economic Affairs, Choice in Welfare, $n^{\circ} 33$, pp. 139-149.

ASHWORTH, K., S. MIDDLETON y R. WALKER (1997), Income Support Dynamics: Evidence From Administrative Data, Loughborough, Centre for Research in Social Policy, CRSP2177.

BELL, L. y J. RIBBENS (1994), "Isolated housewives and complex maternal worlds: the significance of social contacts between women with young children in industrial societies", Sociological Review, 42 (4): 227-262.

BRADSHAW, J. (1998a), "Lone parents", en p. Alcock et al., (ed.) The Student's Companion to Social Policy, Oxford, Blackwell Publishers, pp. 263-270.

(1998b), "International comparisons of support for lone parents", en R. Ford y J. Millar (eds.), Private Lives and Public Responses. Lone Parenthood and Future Policy in the UK, London, Policy Studies Institute, pp. 154-168. 
BRADSHAW, J. y J. MILLAR (1991), Lone Parent Families in the UK, London, HMSO, DSS Research Report, $\mathrm{n}^{\circ} 6$.

BRADSHAW, J. et al., (1996), The Employment of Lone Parents: a Comparison of Policy in 20 Countries, London, Family Policy Studies Centre.

BRYSON, A. (1998), "Lone mothers' earnings", en R. Ford y J. Millar (eds.), Private Lives and Public Responses. Lone Parenthood and Future Policy in the UK, London, Policy Studies Institute, pp. 169-183.

BRYSON, A., R. FORD y M. WHITE (1997), Making Work Pay: Lone Mothers Employment and Well-being, York, Joseph Rowntree Foundation, Work and Opportunity Series, $\mathrm{n}^{\circ} 1$.

BRYSON, A. y S. MCKAY (eds.) (1994), Is It Worth Working? Factors Affecting Labour Supply, London, Policy Studies Institute.

BRYSON, A. y S. MCKAY (1996), Leaving Family Credit, London, The Stationery Office, DSS Report $\mathrm{n}^{\circ} 48$.

BURGHES, L. (1993), One-Parent Families: Policy Options for the 1990s, Nueva York, Joseph Rowntree Foundation.

(1994), Lone Parenthood and Family Disruption: the Outcomes for Children, London, Family Policy Studies Centre.

(1996), "Debates on disruption: What happens to the children of lone parents", en E.B. Silva (ed.), Good Enough Mothering? Feminist Perspectives on Lone Motherhood, London, Routledge, pp. 157-174.

COLEMAN, D. (2000), "Population and family", en A.H. Halsey y J. Webb (eds.), Twentieth-century British Social Trends, London, MacMillan Press, pp. 27-93.

DENNIS, N. (1993), Rising Crime and the Dismembered Family, London, IEA Health and Welfare Unit, Choice in Welfare, $\mathrm{n}^{\circ} 18$.

DENNIS, N. y G. ERDOS (1992), Families without Fatherhood, London, Institute of Economic Affairs, Health and Welfare Unit, Choice in Welfare, $\mathrm{n}^{\circ} 12$.

DHSS (1974), Report of the Committee on One-Parent Families (Finer Report), Cmnd. 5629, London, HMSO.

DEPT. FOR EDUCATION AND EMPLOYMENT (DfEE) (1998), Meeting the Childcare Challenge, London, The Stationary Office.

(1999), Making a Difference for Children and Families, Sure Start, London, The Stationary Office.

DEPARTMENT OF SOCIAL SECURITY (DSS) (1998), Households below Average Income, London, The Stationery Office. 
(2000), Households Below Average Income 1994/95 to 1998/9, London, DSS.

DUNCAN, S. y R. EDWARDS (eds.) (1997), Single Mothers in an International Context: Mothers or Workers?, London, University College London.

(1997a), "A contextual approach to single mothers and paid work", en S. Duncan y R. Edwards (eds.) Single Mothers in an International Context: Mothers or Workers?, London, University College London, pp. 1-8.

(1997b), "Single mothers in Britain: unsupported mothers or workers?", en S. Duncan y R. Edwards (eds.), Single Mothers in an International Context: Mothers or Workers?, London, University College London, pp. 45-80.

(1997c), "Single mothers - mothers versus workers or mothers and workers", en S. Duncan y R. Edwards (Eds.), Single Mothers in an International Context: Mothers or Workers?, London, University College London, pp. 269-275.

(1999), Lone Mothers, Paid Work and Gendered Moral Rationalities, London, MacMillan Press.

DUSKIN, E. (ed.) (1990), "Lone Parent Families: the Economic Challenge", Social Policy Studies, $\mathrm{n}^{\circ} 8$, París, OECD.

EDWARDS, R. y S. DUNCAN (1995), "Rational economic man or lone mothers in social context? The take up of paid work", en E.B. Silva (ed.), Good Enough Mothering. Feminist Perspectives on Lone Motherhood, London, Routledge, pp. 114-129.

ERMISH, J.F. (1991), Lone Parenthood. An Economic Analysis, Cambridge, Cambridge University Press.

ERMISH, J.F., S. JENKINS y R.E. WRIGHT (1990), “Analysis of the dynamics of lone parenthood: socio-economic influences on entry and exit rates", en E. Duskin (ed.), "Lone Parent Families: the Economic Challenge”, Social Policy Studies, nº 8, pp. 69-90, Parí, OECD.

ERMISH, J.F. y R.E. WRIGHT (1991), "Welfare benefits and lone parents' employment in Great Britain”, Journal of Human Resources, 26 (3), pp. 424-456.

EUROSTAT (1998), "Les familles monoparentales: un phénomène qui prend de l'ampleur", Statistiques en Bref, $\mathrm{n}^{\circ} 12$.

(2000), "Social exclusion in the EU member states", Eurostat, Statistics in Focus, Population and Social Conditions, $\mathrm{n}^{\circ} 1$.

ESRC (1994), Changing Households: the British Household Panel Survey 1990-1992, Colchester, ESRC Research Centre on Micro-Social Change.

FINLAYSON, L. y A. MARSH (1998), "Lone parents on the margins of work", en R. Ford y J. Millar (eds.), Private Lives and Public Responses. Lone Parenthood and Future Policy in the $U K$, London, Policy Studies Institute, pp. 193-207. 
FORD, R. (1996), Childcare in the Balance: How Parents Make Decisions about Work, London, Policy Studies Institute.

(1998), "Lone mothers' decisions whether or not to work: childcare in the balance", en R. Ford y J. Millar (eds.) Private Lives and Public Responses. Lone Parenthood and Future Policy in the UK, London, Policy Studies Institute, pp. 208-225.

FORD, R., A. MARSH y S. McKAY (1995), Changes in Lone Parenthood, London, HMSO.

FORD, R. y J. MILLAR (1998), "Lone parenthood in the UK: policy dilemmas and solutions", en R. Ford y J. Millar (eds.), Private Lives and Public Responses. Lone Parenthood and Future Policy in the UK, London, Policy Studies Institute, pp. 1-21.

(eds.) (1998), Private Lives and Public Responses. Lone Parenthood and Future Policy in the UK, London, Policy Studies Institute.

FOX HARDING, L. (1993a), “'Alarm' versus 'liberation'? Responses to the increase in lone parents - Part 1", Journal of Social Welfare and Family Law, 2, pp. 101-112.

(1993b), “'Alarm' versus 'liberation'? Responses to the increase in lone parents - Part 2", Journal of Social Welfare and Family Law, 3, pp. 174-184.

(1996), “'Parental responsibility': the reassertion of private patriarchy?”, en E.B. Silva (ed.), Good Enough Mothering? Feminist Perspectives on Lone Motherhood, London, Routledge, pp. 130-147.

FURSTENBERG, F.F. Jr. y A.J. CHERLIN (1991), Divided Families: What Happens to Children When Parents Part?, Cambridge, Mass., Harvard University Press.

GARDINER, K. (1997), Bridges from Benefit to Work. A Review, Joseph Rowntree Foundation, Work and Opportunity Series, $n^{\circ} 2$.

GLENDINNING, C. y J. MILLAR (eds.) (1992), Women and Poverty in Britain. The 1990s, Hemel Hempstead, Harvester/Wheatsheaf.

HASKEY, J. (1998), “One-parent families and their dependent children in Britain”, en R. Ford y J. Millar (eds.), Private Lives and Public Responses. Lone Parenthood and Future Policy in the UK, London, Policy Studies Institute, pp. 22-41.

HM TREASURY (1999), The Modernisation of Britain's Tax and Benefit System, No. 5: Supporting Children Through the Tax and Benefit System, London, HM Treasury, November.

(2000), Budget 2000, London, HM Treasury.

HOBCRAFT, J. y K. KIERNAN (1999), Childhood Poverty, Early Motherhood and Adult Social Exclusion, LSE and Toyota International Centre, Economic and Social Research Council (ESRC), Case-paper 28.

HOLTERMAN, S. (1993), Becoming a Breadwinner: Policies to Assist Lone Parents With Childcare, London, Daycare Trust. 
RIS

RETISTA INTERNACIONAL DE SOCIOLOGIA

№ 30. Septiembre-Diciembre, 2001

CARMEN RODRIGULZ SUMAZA

JARVIS, S. y S.P. JENKINS (1998), "Marital dissolution and income change: evidence for Britain", en R. Ford y J. Millar (eds.), Private Lives and Public Responses. Lone Parenthood and Future Policy in the UK, London, Policy Studies Institute, pp. 104-117.

JENKINS, S.P. (1992), "Lone mothers' employment and full-time work probabilities", The Economic Journal, 102 (411), pp. 310-320.

JOSHI, H. (1990), "Obstacles and opportunities for lone parents as breadwinners in Great Britain", en E. Duskin (ed.), "Lone Parent Families: the Economic Challenge", Social Policy Studies, $\mathrm{n}^{\circ} 8$, pp. 127-150, Paris, OECD.

KELLY, R. (2000), Reforming the WFTC. How an Integrated Child Credit Could Work for Children and Families, London, The Fawcett Society, Occasional Paper.

KIERNAN, K., H. LAND y J. LEWIS (1998), Lone Motherhood in Twentieth-Century Britain, Oxford, Clarendon Press.

LAND, H. y J. LEWIS (1998), "The problem of lone motherhood in the British context", en R. Ford y J. Millar (eds.), Private Lives and Public Responses. Lone Parenthood and Future Policy in the UK, London, Policy Studies Institute, pp. 141-153.

LEWIS, J. (1989), "Lone parent families: politics and economics", Journal of Social Policy, vol. $18, n^{\circ} 4$, pp. $595-600$.

(1992), "Gender and the development of welfare regimes", Journal of European Social Policy, $\mathrm{n}^{\circ} 2$, pp. 159-173.

(1997), "Lone mothers: the British case", en J. Lewis (ed.), Lone Mothers in European Welfare Regimes. Shifting Policy Logics, London, Jessica Kingsley Publishers, pp. 50-75.

(1998), "The problem of lone-mother families in twentieth-century Britain", The Journal of Social Welfare and Family Law, vol. 20, n 3, pp. 251-284.

(1999), "The 'problem' of lone motherhood in comparative perspective", en J. Clasen (ed.), Comparative Social Policy: Concepts, Theories and Methods, Oxford, Blackwell Publishers, pp. 181-199.

LEWIS, J. y B. HOBSON (1997), "Introduction", en J. Lewis (ed.), Lone Mothers in European Welfare Regimes. Shifting Policy Logics, London, Jessica Kingsley Publishers, pp. 1-20.

LISTER, R. (ed.) (1996), Charles Murray and the Underclass. The Developing Debate, London, Institute of Economic Affairs, Choice in Welfare, $\mathrm{n}^{\circ} 33$.

MARSH, A., R. FORD y L. FINLAYSON (1997), Lone Parents, Work and Benefits, Dept. of Social Security, Research Report $\mathrm{n}^{\circ}$ 61, London, The Stationery Office.

MARSH, S. y A. McKAY (1993), Families, Work and Benefits, London, Policy Studies Institute.

McINTOSH, M. (1996), "Social anxieties about lone motherhood and ideologies of the family: two sides of the same coin", en E.B. Silva (ed.) Good Enough Mothering? Feminist Perspectives 
on Lone Mother/hood, London, Routledge, pp. 148-156.

McKAY, S. y A. MARSH (1994), Lone Parents and Work, London, HMSO.

McKAY, S. y K. ROWLINGSON (1998), "Choosing lone parenthood? The dynamics of family change”, en R. Ford y J. Millar, J. (eds.), Private Lives and Public Responses. Lone Parenthood and Future Policy in the UK, London, Policy Studies Institute, pp. 42-57.

MCKENDRICK, J. (1998), "The 'big' picture: quality in the lives of lone parents", en R. Ford y J. Millar, J. (eds.), Private Lives and Public Responses. Lone Parenthood and Future Policy in the UK, London, Policy Studies Institute, pp. 78-103.

McLAUGHLIN, E., J. MILLAR y K. COOKE (1989), Work and Welfare Benefits, Avebury, Gower Publising Company.

MIDDLETON, S. y K. ASHWORTH (1998), "Small fortunes: spending on children in lone-parent families", en R. Ford y J. Millar, J. (eds.) Private Lives and Public Responses. Lone Parenthood and Future Policy in the UK, London, Policy Studies Institute, pp. 118-140.

MILlar, J. (1989), Poverty and the Lone Parent Family: the Challenge to Social Policy, Aldershot, Avebury Press.

(1992), "Lone mothers and poverty", en C. Glendinning y J. Millar (eds.), Women and Poverty in Britain: the 1990 's, Hemel Hempstead, Harvester/Wheatsheaf, pp. 129-148.

(1996a), "Mothers, workers, wives: comparing policy approaches to supporting lone mothers", en E.B. Silva (ed.), Good Enough Mothering? Feminist Perspectives on Lone Motherhood, London, Routledge, pp. 97-113.

(1996b), "Women, poverty and social security", en C. Hallet (ed.), Women and Social Policy: An Introduction, London, Prentice Hall, pp. 52-64.

MILLAR, J. y J. BRADSHAW (1987), "The living standards of lone parent families", Quarterly Journal of Social Affairs, vol. 3, n² 2, pp. 233-252.

MILLAR, J. y C. GLENDINNING (1992), "'It all really starts in the family": gender divisions and poverty", en C. Glendinning and J. Millar (eds.), Women and Poverty in Britain. The 1990s, Hemel Hempstead, Harvester/Wheatsheaf, pp. 3-10.

MILLAR, J., S. WEBB y M. KEMP (1997), Combining Work and Welfare, York, Joseph Rowntree Foundation, Work and Opportunity Series, $\mathrm{n}^{\circ} 3$.

MORGAN, P. (1995), Farewell to the Family? Public Policies and Family Breakdown in Britain and the USA, London, IEA Health and Welfare Unit, Choice in Welfare, $\mathrm{n}^{\circ} 21$.

MOSS, P. (1991), "Daycare policy and provision in Britain”, en P. Moss y E. Melhuish (eds.), Current Issues in Day Care for Young Children, London, HMSO.

MURRAY, C. (1990), The Emerging British Underclass, London, Institute of Economic Affairs, Health and Welfare Unit. 
(1994), Underclass: the Crisis Deepens, London, Institute of Economic Affairs, Health and Welfare Unit, Choice in Welfare Series, $\mathrm{n}^{\circ} 20$.

NOBLE, M., S.Y. CHEUNG y G. SMITH (1998), "Origins and Destinations - Social Security Claimant Dynamics”, Journal of Social Policy, 27 (3): 351-369.

NOBLE, M., G. SMITH y S.Y. CHEUNG (1998), Lone Mothers Moving In and Out of Benefits, York, Joseph Rowntree Foundation, Work and Opportunity Series, $\mathrm{n}^{\circ} 4$.

OFFICE FOR NATIONAL STATISTICS (ONS) (2000), Social Trends, London, The Stationery Office, Vol. 30.

OPPENHEIM, C. (1998), "An overview of poverty and social exclusion", en C. Oppenheim (ed.), An Inclusive Society. Strategies for Tackling Poverty, London, Institute for Public Policy Research (IPPR), pp. 11-28.

PHOENIX, A. (1996), "Social constructions of lone motherhood: a case of competing discourses", en E.B. Silva (ed.), Good Enough Mothering? Feminist Perspectives on Lone Motherhood, London, Routledge, pp. 175-190.

POLACHEK, S.W. (1995), "Earnings over the life cycle: what do human capital models explain?", Scottish Journal of Political Economy, vol. 43, $\mathrm{n}^{\circ} 3$, pp. 267-289.

POPAY, J., L. RIMMER y C. ROSSITER (1983), One Parent Families. Parents, Children and Public Policy, London, Study Commission on the Family, Occasional Paper, $\mathrm{n}^{\circ} 12$.

RODGERS, B. y J. PRYOR (1998), Divorce and Separation. The Outcomes for Children, Nueva York, Joseph Rowntree Foundation.

RODRÍGUEZ SUMAZA, C. (2000), "Lone Parent Families within New Labour Welfare Reform”, Contemporary Politics, vol. 7, $\mathrm{n}^{\circ}$ 3, sept., p. 231-247.

ROLL, J. (1992), Lone Parent Families in the European Community, Brussels, EC Commission.

ROSENEIL, S. y K. MANN (1996), "Unpalatable choices and inadequate families: lone mothers and the underclass debate", en E.B. Silva (ed.), Good Enough Mothering? Feminist Perspectives on Lone Motherhood, London, Routledge, pp. 191-210.

ROWLLINGSON, K. y S. MCKAY (1998), The Growth of Lone Parenthood: Diversity and Dynamics, London, Policy Studies Institute.

SCOTT, J., M. BRAUN y D. ALWIN (1998), "Partner, parent, worker: family and gender

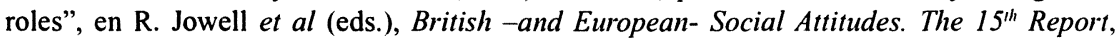
Aldershot, Ashgate, pp. 19-38.

SHAW, A. et al., (1996), Moving Off Income Support: Barriers and Bridges, DSS Research Report, $\mathrm{n}^{\circ}$ 53, London, HMSO.

SILVA, E.B. (ed.) (1996), Good Enough Mothering? Feminist Perspectives on Lone Motherhood, London, Routledge. 
SONG, M. (1996), "Changing conceptualisations of lone parenthood in Britain: lone parents or single mums", European Journal of Women's Studies, 3 (4), pp. 377-397.

STACEY, J. (1994), "Scents, scholars and stigma: the revisionist campaign for family values", Social Text, 40, pp. 51-75.

STOLTZ, P. (1997), "Single mothers and the dilemmas of universal social policies", Journal of Social Policy, 26 (4), pp. 425-443.

UTTING, D. (1995), Family and Parenthood: Supporting Families, Preventing Breakdown, Nueva York, Joseph Rowntree Foundation. 